\title{
DIAGRAMAS DE APOIO AO PROJETO BASEADOS NA IDEIA DO CONFORTO TÉRMICO ADAPTATIVO
}

\section{SUPPORTIVE DIAGRAMS FOR THE BUILDING DESIGN PROCESS BASED ON THE ADAPTIVE THERMAL COMFORT MODEL}

\author{
Leandro Carlos Fernandes ${ }^{1}$ \\ Universidade Federal do Paraná, Curitiba, PR, Brasil, fernandes.ufpr@gmail.com
}

\begin{abstract}
Resumo
Diagramas podem ser utilizados para análise de problemas complexos, facilitando decisões. Como exemplo, citam-se os diagramas bioclimáticos, utilizados para definir diretrizes para projetos de edificações. Contudo, por serem baseados em modelos de conforto térmico estáticos, os diagramas bioclimáticos não são compatíveis com a ideia do conforto térmico adaptativo. Esta pesquisa teve por objetivo apresentar diagramas de apoio ao processo de projeto de pequenas edificações de baixo consumo energético e adequados à ideia do conforto adaptativo. A partir de um modelo adaptativo de conforto e dos diagramas existentes, elaboraram-se dois diagramas e procedimentos para sua aplicação. Os diagramas foram aplicados às fases iniciais do processo de projeto de pequenas edificações no clima de Curitiba e os resultados foram comparados com os obtidos com o tradicional diagrama de Givoni. A comparação mostrou que as diferenças entre os modelos de conforto resultam em diretrizes diferentes. $O$ método alternativo também permitiu analisar mais adequadamente a variável amplitude térmica diária e ordenar a aplicação das diretrizes projetuais.
\end{abstract}

Palavras-chave: Diagramas antropoclimáticos. Análise climática. Conforto térmico adaptativo. Abordagem bioclimática. nZEB.

\begin{abstract}
Diagrams can be used to analyze complex problems, facilitating decisions. As an example, we could mention the bioclimatic diagrams used to define guidelines for building design. However, bioclimatic diagrams are not compatible with the idea of adaptive thermal comfort. This research aimed to present diagrams to support the design process of small buildings with low energy demand and suitable for the concept of adaptive comfort. Based on an adaptive comfort model and existing diagrams, two diagrams and procedures for its application were elaborated. The diagrams were applied to the early design phases of small buildings' design process in Curitiba's climate. The results were compared with those obtained with the traditional Givoni diagram. The comparison showed that the differences between both comfort models result in different guidelines. The alternative method also allowed an adequate analysis of the daily temperature range and ordered the design guidelines' application.
\end{abstract}

Keywords: Anthropoclimatic diagrams. Climate analysis. Adaptive thermal comfort. Bioclimatic approach. nZEB.

How to cite this article:

FERNANDES, Leandro Carlos. Diagramas de apoio ao projeto baseados na ideia do conforto térmico adaptativo. PARC

Pesquisa em Arquitetura e Construção, Campinas, SP, v. 11, p. e020030, 2020.

DOI:http://dx.doi.org/10.20396/parc.v11i0.8657295

\section{Introdução}

Os diagramas são ferramentas abstratas usadas para representar, compreender e condensar informações de difícil tradução discursiva. São próprios para abordagem de problemas complexos, com múltiplas variáveis.

Em arquitetura e urbanismo, diagramas para diagnóstico de problemas, identificação de potencialidades e avaliação de diretrizes projetuais são pouco empregados. Uma das áreas próprias para a aplicação destas ferramentas é a das edificações de consumo energético quase nulo (nearly Zero Energy Building - nZEB). Nestas, considerando que as pessoas passam aproximadamente $90 \%$ do seu tempo em edificações (JUNKER; KOLLER; MONN, 2000), o adequado condicionamento térmico é fundamental. 
Atualmente, conta-se com os diagramas bioclimáticos. São diagramas avaliativos, alimentados por dados numéricos do clima e demandas ambientais humanas.

O termo bioclima foi originalmente pensado por Wladimir Peter Köppen (RUBEL; KOTTEK, 2011), climatólogo que, em 1900, lançou seu sistema de classificação climática relacionando clima e vegetação. Köppen acreditava que a vegetação (ou a vida adaptada ao ambiente) é o melhor reflexo do clima, servindo como referência para classificá-lo. Posteriormente, Olgyay (2008) utilizou o termo "abordagem bioclimática" para relacionar clima e edificações. Olgyay procurou demonstrar que a arquitetura vernacular é resultado das condições locais. A inspiração nas ideias de Köppen é explícita na obra "Arquitectura y clima: manual de diseño bioclimático para arquitectos y urbanistas" (OLGYAY, 2008), na qual o climatólogo é citado.

O Diagrama Bioclimático de Olgyay relaciona a Temperatura de Bulbo Seco $\left(T_{a b s}\right)$ com a Umidade Relativa (UR). Elaborado sobre o diagrama psicrométrico do ar, foi desenvolvido para a zona de clima temperado dos EUA, mas pode ser adaptado para outros locais defasando a zona de conforto em 2 a $3{ }^{\circ} \mathrm{C}$ (para mais em zonas quentes e para menos em frias) (OLGYAY, 2008).

Givoni (1992), adaptando o diagrama de Olgyay, desenvolveu uma proposta que chamou de "Building Bio-Climatic Chart - BBCC". Givoni observou que existe uma relação inversa entre as variáveis ambientais amplitude térmica e pressão atual do vapor d'água (Equação 1). Ou seja, existe uma relação inversa entre a UR e a amplitude térmica. Em função dessa relação, o autor propôs as zonas 'massa térmica alta', 'massa térmica alta com ventilação noturna' e 'aquecimento solar passivo'.

$$
\Delta T m=26-0,83 \times P_{v} \quad \text { Equação } 1
$$

Fonte: Givoni (1992).

Na qual, $\Delta T_{m}$ é a média das amplitudes térmicas diárias de um mês e $P_{v}$ é a média da pressão atual de vapor desse período.

A adequação do desempenho térmico das edificações está associada à correta relação entre a inércia térmica e as amplitudes térmicas diárias $\left(\Delta T_{d}\right)$ do clima de implantação. Em climas com altas amplitudes térmicas diárias, altos níveis de inércia térmica (NIT) são recomendados para moderar as oscilações térmica internas (VERBEKE; AUDENAERT, 2018). Dentre as estratégias para se atingir os níveis de inércia térmica desejados, citamse: a) ajustar os níveis de massa térmica das paredes internas e externas (podendo resultar em isolamento capacitivo); e b) somar à estratégia anterior a aplicação de materiais super isolantes (isolamento resistivo) nas paredes externas, resultando em massa térmica + isolamento capacitivo + resistivo. O isolamento capacitivo é obtido, em regimes com oscilação periódica de temperaturas, aplicando-se materiais pesados nas paredes externas, os quais absorverão e acumularão energia, resultando em isolamento térmico (ZÖLD; SZOKOLAY, 1997).

Pelo menos três autores consideraram a $\Delta T$ com vista ao estabelecimento de diretrizes de projeto: Evans (2003) a utilizou como uma das variáveis de entrada de seu diagrama; Mahoney (SZOKOLAY, 2008) a utilizava nas 'tabelas de Mahoney'; e Givoni (1992) a considerava indiretamente, via relação com a pressão atual de vapor e umidade relativa.

A $\Delta T$ também é utilizada para caracterizar climas. O clima quente e seco é descrito como com alta $\Delta T_{d}$; o quente e úmido como com baixa $\Delta T_{d}$; e os temperados como com $\Delta T_{d}$ variadas ao longo do ano (GIVONI, 1992).

Givoni também desenvolveu o "índice de stress térmico" para traduzir numericamente a sensação térmica e apoiar o seu diagrama. O índice combina a $T_{b s}$, a temperatura de 
bulbo úmido $\left(T_{b u}\right)$ e a velocidade do $\operatorname{ar}\left(V_{a}\right)$. A exemplo de Olgyay, Givoni definiu zonas de conforto/desconforto: para inverno, de 18 a $25^{\circ} \mathrm{C}$; e para verão, de 20 a $27^{\circ} \mathrm{C}$, com $\Delta T_{d}$ interna máxima de $7{ }^{\circ} \mathrm{C}$. Para países com clima quente e/ou considerados "em desenvolvimento", Givoni (1992) recomenda que os limites superiores das faixas de conforto sejam aumentados em $2{ }^{\circ} \mathrm{C}$. Enquanto Olgyay optou por plotar seu diagrama sobre a carta psicrométrica de forma discreta, Givoni optou pela plotagem explícita.

Evans (2003), apresentou um diagrama (Triângulos de Evans) relacionando temperaturas médias mensais com as respectivas amplitudes térmicas mensais. $O$ diagrama apresenta zonas de conforto para: atividades sedentárias (A); repouso (B); circulação interna (C); e circulação externa (D).

Para o Brasil, Bogo et al. (1994) propuseram um diagrama bioclimático adaptando a carta de Givoni. Não foram adotadas as duas zonas para conforto propostas por Givoni (1992), uma para inverno e outra para verão. Optou-se por uma única zona (18 a $29^{\circ} \mathrm{C}$ ), abrangendo as duas anteriores, mais os $2{ }^{\circ} \mathrm{C}$ para países em desenvolvimento, com amplitude de $11^{\circ} \mathrm{C}$.

Os modelos de conforto térmico dos diagramas listados até aqui contrastam com os modelos adaptativos de conforto térmico. Nestes, considera-se que, em edificações condicionadas naturalmente, os usuários se adequam às condições internas ajustando a vestimenta, a taxa metabólica e adequando a edificação. Considera-se ainda que, ao longo das estações, os usuários sofrem aclimatação. Vários autores apresentaram modelos de conforto adaptativos relacionando temperaturas neutras com médias de temperaturas externas (HUMPHREYS, 1976 apud NICOL, 2002; HUMPHREYS, 2002; AULICIEMS, 1983; DEAR; BRAGER; COOPER, 1997).

Entre os modelos adaptativos de conforto térmico disponíveis, está o da norma ANSI/ASHRAE Standard 55 (ASHRAE, 2017) para edificações condicionadas naturalmente (Equação 2).

$$
T_{\text {o conf }}=0,31 T_{\text {a ex } m ~}+17,8^{\circ} \mathrm{C}
$$

Equação 2

Fonte: ASHRAE (2017).

Na qual, $T_{\text {oconf }}$ é a temperatura operativa neutra e $T_{\text {aexmm }}$ é a média aritmética móvel das temperaturas externas $\left({ }^{\circ} \mathrm{C}\right)$.

O modelo desta norma é aplicável quando as temperaturas médias mensais forem $\geq 10$ ${ }^{\circ} \mathrm{C}$ e $\leq \mathrm{a} 33,5^{\circ} \mathrm{C}$. A $T_{\text {a exmm } m}$ deve ser baseada em não menos do que sete e não mais do que 30 dias consecutivos antes do dia em questão (ASHRAE, 2017). Em torno da $T_{\text {o conf }}$ são definidas duas faixas de aceitabilidade térmica: com $5{ }^{\circ} \mathrm{C}$ de largura, para $90 \% \mathrm{da}$ população; e com $7{ }^{\circ} \mathrm{C}$ de largura, para $80 \%$ da população (Figura 1).

Alguns pesquisadores defendem estudos para contemplar, nos modelos adaptativos, os efeitos da umidade relativa sobre o conforto térmico (VELLEI et al., 2017). No entanto, os modelos considerando apenas temperaturas seguem hegemônicos. No contexto apresentado, identificam-se alguns problemas.

O diagrama de Evans (2003) contempla a $\Delta T$ explicitamente, porém, trabalha com médias mensais. Givoni (1992) aborda a $\Delta T$ indiretamente, no entanto, quando o diagrama é utilizado com dados horários, dias com grandes $\Delta T$ terão seus dados distribuídos por zonas muito diferentes. Um dia com $T_{a}$ variando de 9 a $30{ }^{\circ} \mathrm{C}$ pode ter seus 24 pontos distribuídos por zonas como: aquecimento artificial; aquecimento solar; massa térmica para aquecimento; conforto; sombreamento; massa térmica para resfriamento; e ventilação natural, resultando em recomendações opostas para um mesmo dia. 
Figura 1 - Faixas aceitáveis para espaços condicionados naturalmente

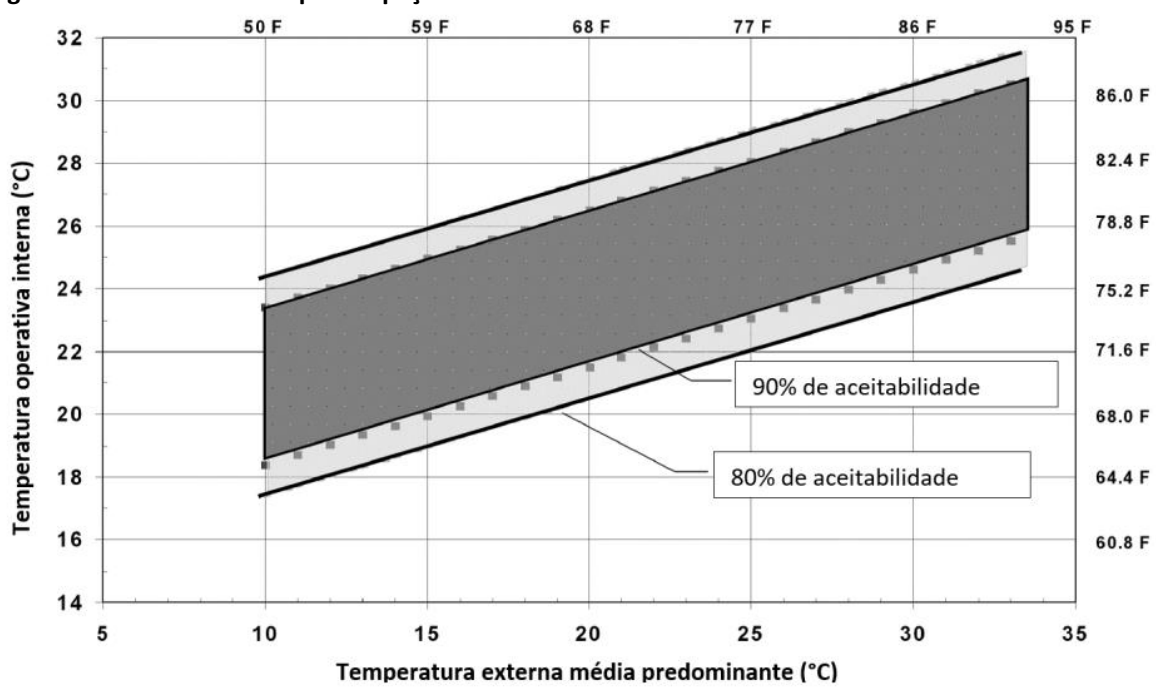

Fonte: Adaptada de ASHRAE (2017)

Os diagramas de Olgyay (2008), Givoni (1992) e Evans (2003) também carecem de ordenamento quanto às estratégias a serem utilizadas e desconsideram que as estratégias impactam umas nas outras. Por exemplo, em climas com temperaturas médias confortáveis, aumentar a inércia térmica para reduzir a $\Delta T_{d}$ pode eliminar a demanda por resfriamento e/ou aquecimento, sem que sejam necessárias outras medidas para aquecimento/resfriamento. Os diagramas de Olgyay, Givoni, Bogo e Evans apresentam faixas estáticas e não são ajustados à ideia da aclimatação. Os diagramas adaptativos não apresentam zonas com diretrizes para projeto.

O objetivo deste trabalho foi apresentar diagramas de apoio ao processo de projeto adaptados à ideia do conforto térmico adaptativo e voltados para pequenas edificações com consumo energético quase nulo (nZEB).

\section{Procedimentos metodológicos}

Neste trabalho, pequenas edificações são entendidas como formas de antropização do ambiente. Possibilitam intervir nas condições microclimáticas para adequá-las às demandas das atividades humanas. Os diagramas aqui apresentados são ferramentas de apoio à antropização desses microclimas e são chamados de Diagrama Antropoclimático 1 (DA1) e Diagrama Antropoclimático 2 (DA2).

\section{Fundamentos teóricos do método apresentado}

Os procedimentos aqui descritos consideram que:

1) A temperatura do ar é a principal variável a ser considerada quando o tema é conforto térmico em edificações (DE DEAR; BRAGER; COOPER, 1997).

2) Deve-se focar no controle de dois aspectos da temperatura do ar para obtenção de ambientes térmicos internos moderados comparativamente aos externos e adequados às atividades humanas: a flutuação (amplitudes térmicas diárias) e a posição que seus valores ocupam em relação à faixa de valores confortáveis.

3) O projeto de um ambiente térmico interno parte de um ambiente similar ao ambiente externo sombreado. Ao longo do projeto, em etapas sucessivas, dota-se esse ambiente térmico interno de características próprias. Nesta perspectiva, o 
objeto é o ambiente térmico. A edificação é o conjunto de artifícios utilizados para obter o ambiente térmico almejado.

4) As decisões de projeto são interimpactantes e devem acontecer em etapas. Por isso, foram propostas duas etapas principais de análise para evitar que a adoção de uma estratégia anule a adotada anteriormente.

Inicia-se com uma edificação hipotética, cujo ambiente interno apresenta amplitudes térmicas diárias $\left(\Delta T_{d}\right)$ e temperaturas do $\operatorname{ar}\left(T_{a}\right)$ idênticas àquelas do ambiente externo. Essa edificação é:

- Absolutamente leve (nível de inércia térmica igual a zero);

- Possui revestimentos reflexivos (baixa absorção de radiação térmica) e dispositivos para sombreamento;

- -Não dispõe de artifícios para aquecimento/resfriamento (as trocas térmicas se dão exclusivamente por condução e convecção).

Primeiramente, deve-se moderar a flutuação (amplitude) das temperaturas e, depois, ajustar a faixa em que elas ocorrem para que coincida com a faixa de conforto.

Ordenadamente, características são agregadas e alteradas, regulando o impacto do ambiente externo sobre o interno, que vai se diferenciando do primeiro, adequando-se ao modelo adaptativo adotado.

\section{Modelo adaptativo adotado}

Para estruturação dos diagramas antropoclimáticos, o modelo adaptativo apresentado pela ASHRAE (2017) foi utilizado. É o modelo utilizado no projeto de revisão da parte 2 da ABNT/NBR 16401 (ABNT/CB-055, 2016). A temperatura neutra e a faixa com aceitabilidade de $90 \%$ da ASHRAE (2017) são muito próximas das do modelo adaptativo proposto por Auliciems (1983), indicado por Pereira e Assis (2010) como o mais apropriado para as condições brasileiras.

Dados de entrada e dados derivados

Como dados de entrada, foram utilizadas as temperaturas externas do $\operatorname{ar}\left(T_{a}\right.$ ex $)$ e a latitude local. Estas foram processadas para se obter as variáveis:

a) Temperaturas médias diárias $\left(T_{a \text { exm }}\right)$;

b) Amplitudes térmicas diárias $\left(\Delta T_{d}\right)$;

c) Temperaturas médias móveis dos últimos 30 dias ( $T_{a \text { ex m m }}$ );

d) Temperaturas operativas neutras ( $\left.T_{\text {o conf }}\right)$.

Os dados utilizados neste artigo foram obtidos de arquivos climáticos em formato TRY (Test Reference Year) disponíveis no site www.labeee.ufsc.br. Dados referentes à região de Curitiba (ano 2008, latitude $25^{\circ} 27^{\prime} \mathrm{S}$ e altitude $910 \mathrm{~m}$ ) foram utilizados. No zoneamento bioclimático brasileiro, o clima de Curitiba pertence à Zona 1 (ABNT, 2005).

\section{Diferenciação dos períodos diurno e noturno}

O valor da latitude permitiu calcular os horários do nascer e do pôr do sol (Equações $3 \mathrm{e}$ 4), possibilitando diferenciar os períodos diurno e noturno.

$$
\delta=23,45 \times \operatorname{sen}\left(\frac{360}{365} \times(284+n)\right) \quad \text { Equação } 3
$$




$$
T d=\left(\frac{2}{15}\right) \times \arccos (-\tan \emptyset \times \tan \delta) \quad \text { Equação } 4
$$

$\delta$ é a declinação solar, $n$ é o dia sequencial do ano (de 1 a 365), Td é a duração do dia (em horas) e $\varnothing$ é a latitude local (valor negativo para locais no hemisfério sul). 12 menos $T d / 2$ retornará o horário do nascer do sol e 12 mais $T d / 2$ o horário do pôr do sol.

Nível de Inércia Térmica (NIT) e Nível de Inércia Térmica Relativo Recomendado (NITRR)

Um dos índices mais utilizados para mensurar a inércia térmica é o fator decremental (F). É definido como a razão entre a amplitude térmica diária interna $\left(\Delta T_{d}\right.$ in $)$ e a amplitude térmica diária externa ( $\Delta T_{d}$ in) (Equação 5 ). Trabalha com a ideia de porcentagem, indicando a porcentagem que a $\Delta T_{\text {din }}$ representa da $\Delta T_{\text {dex }}$. Quanto menor seu valor, maior será a inércia da edificação.

$$
F=\frac{\Delta T_{d i n}}{\Delta T_{d e x}}
$$

Equação 5

O F não é intuitivo para descrever a capacidade de inércia térmica (capacidade de amortecer as flutuações térmicas), pois o valor do $\mathrm{F}$ diminui conforme aumenta a inércia da edificação. Em vista disso, um índice baseado na ideia de fração é proposto nesta pesquisa - o Nível de inércia térmica (NIT). O NIT indica a capacidade da edificação de resistir às flutuações das temperaturas externas. Quanto maior o NIT, maior essa capacidade. É expresso como a razão entre a amplitude térmica diária do ambiente externo e a amplitude térmica diária do interno (Equação 6).

$$
N I T=\frac{\Delta T_{d \text { ex }}}{\Delta T_{\text {din }}}-1
$$

Equação 6

Quando a amplitude térmica diária de uma edificação é igual à amplitude externa, seu NIT é zero (ela não possui inércia). Quando a amplitude interna é menor que a externa, o NIT será positivo. E quando a amplitude interna for maior que a externa, o NIT será negativo. O NIT pode aumentar indefinidamente e constitui um índice mais prático do que o valor percentual variando entre zero e $100 \%$, utilizado no conceito $F$. Outra vantagem é estabelecer uma escala universal, possibilitando comparar níveis de inércia de diferentes edificações, mesmo quando em climas diferentes.

Quando adotado um modelo de conforto térmico que estabelece amplitudes térmicas internas máximas, propõe-se uma variação do NIT chamada Nível de Inércia Térmica Relativo Recomendado (NITRR). O NITRR de uma edificação expressa a relação entre a amplitude térmica diária externa máxima $\left(\Delta T_{\text {d ex máx }}\right)$ do clima para o qual se projeta e a

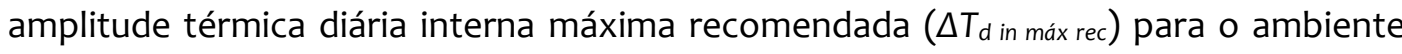
interno (Equação 7). Em se tratando do modelo adaptativo da ANSI/ASHRAE 55 (2017), prevendo $90 \%$ de aceitabilidade, o valor para a $\Delta T_{\text {d in máx rec }}$ é $5{ }^{\circ} \mathrm{C}$ (ASHRAE, 2017).

$$
N I T R R=\frac{\Delta T_{\text {d ex máx }}}{\Delta T_{\text {d in máx rec }}}-1
$$

Equação 7

\section{Diagrama Antropoclimático 1 (DA1) - Análise dos dados do ambiente externo}

O DA1 é utilizado exclusivamente para análise de dados do ambiente externo e possui dois objetivos principais:

- Determinar NITRR para adequação das amplitudes térmicas da edificação;

- Determinar a estratégia para atingir esse NITRR. 
Nesta pesquisa, são analisadas duas das estratégias possíveis para atingir o NITRR: 'massa térmica' e 'massa térmica + isolamento capacitivo e resistivo'.

\section{Estrutura do DA1}

O DA1 é estruturado por um reticulado definido por um eixo horizontal e um semieixo vertical (Figura 2):

a) O eixo horizontal indica as diferenças entre as temperaturas externas e as temperaturas operativas neutras. Perpendicularmente a esse eixo, em seu ponto zero, foi traçada a 'semirreta de neutralidade térmica'. Em torno desta, foi indicada a faixa de conforto para $90 \%$ de aceitabilidade $\left( \pm 2,5^{\circ} \mathrm{C}\right)$. Este eixo também pode ser adaptado para 'eixo de sensação térmica', graduado segundo a escala Predicted Mean Vote (PMV). Neste caso a faixa de conforto tem como limites os valores $\pm 0,50$.

b) No semieixo vertical, marcam-se as amplitudes térmicas diárias. Na base desse semieixo foi indicada a faixa correspondente às amplitudes térmicas diárias internas aceitáveis $\left(\leq 5^{\circ} \mathrm{C}\right)$.

c) A partir da base da faixa de conforto, são traçadas duas semirretas inclinadas, determinando uma faixa em forma de ' $V$ '. A largura dessa faixa aumenta conforme aumentam os valores indicados no semieixo das $\Delta T_{\text {d. }}$. Essa largura é igual à soma do valor da $\Delta T_{d}$, no dia de interesse, com a largura da faixa de conforto. A região delimitada por esta faixa corresponde à região na qual a $\Delta T_{\text {din }}$ pode ser reduzida com isolamento capacitivo e massa térmica interna. À esquerda e à direita dessa faixa, além da massa térmica e do isolamento capacitivo, é necessário utilizar isolamento resistivo. À esquerda, para evitar perdas térmicas e, à direita, para evitar ganhos.

d) Paralelamente ao semieixo das $\Delta T_{d}$ foi definido o semieixo secundário Nível de Inércia Térmica Relativo Recomendado (NITRR). Indica o nível de inércia térmica demandado por uma edificação para que sua $\Delta T_{d}$ seja compatível como o modelo adaptativo adotado.

No futuro, com o aprimoramento do método, pretende-se adicionar um eixo indicando níveis de resistência térmica para as condições de inverno e verão.

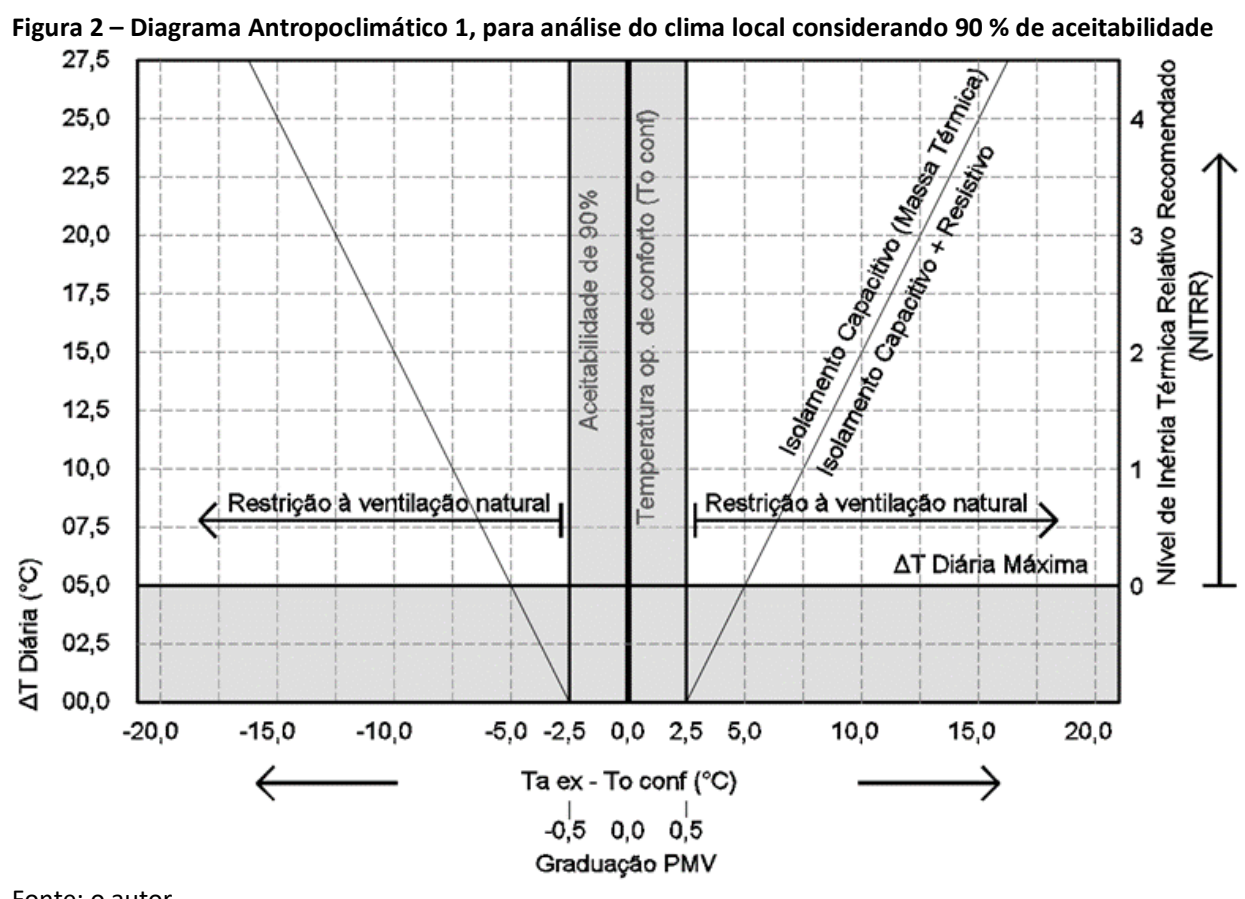

Fonte: o autor. 


\section{Procedimentos para aplicação do DA1}

A plotagem dos dados é feita da seguinte maneira:

1) Para cada dia, calcula-se a $\Delta T_{d}$.

2) Para cada hora do dia, calcula-se a diferença entre a $T_{a \text { ex }}$ e a $T_{\text {o conf. }}$

3) Os 24 valores resultantes, para cada hora do dia, são plotados na altura correspondente à $\Delta T_{d}$ calculada.

A Figura 3 apresenta um exemplo para um dia em que a $\Delta T_{d}$ é $20{ }^{\circ} \mathrm{C}$. Os círculos preenchidos representam as diferenças de temperatura nas horas noturnas e os vazios nas diurnas.

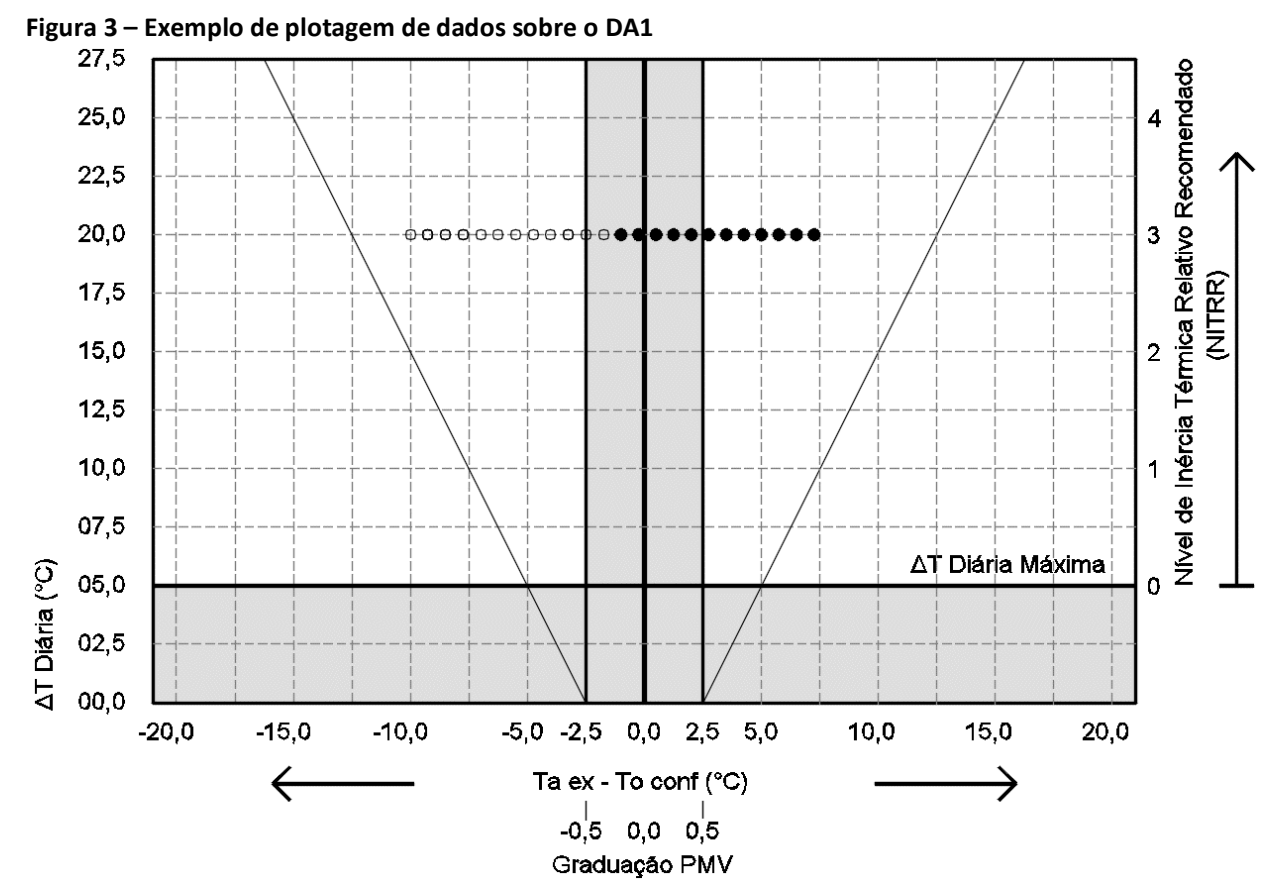

Fonte: o autor.

O primeiro objetivo da plotagem dos dados sobre o DA1 é obter o valor para o NITRR. Ele pode ser lido diretamente do diagrama, indicado no semieixo secundário, no lado direito, ou calculado utilizando a Equação 7.

Considerando que mais inércia pode significar um custo financeiro maior, cabe ao projetista ponderar se utiliza a $\Delta T_{d \text { ex máx }}$ ou se, a fim de desconsiderar as $\Delta T_{d}$ excepcionais, utiliza valores definidos por percentis. Sugere-se utilizar o valor dado pelo percentil 99, desconsiderando $1 \%$ das amplitudes mais altas.

O segundo objetivo da plotagem de dados sobre o DA1 é determinar a estratégia de projeto para atingir esse NITRR. Dentre as possibilidades, as principais opções são:

a) Isolamento capacitivo associado à massa térmica das paredes internas. É aplicado caso as diferenças entre as $T_{a \text { ex } m}$ e as $T_{\text {o conf }}$ permaneçam sobre a faixa de conforto e as diferenças entre $T_{a \text { ex }}$ e as $T_{\text {o conf }}$ permaneçam entre as linhas indicadoras dessa estratégia.

b) Isolamentos capacitivo e resistivo (isolantes de alto desempenho aplicados sobre as superfícies externas) associado à massa térmica das paredes internas. É a opção caso as diferenças entre as $T_{a}$ ex $m$ e as $T_{o}$ conf não permaneçam sobre a faixa de conforto e as diferenças entre $T_{a}$ ex e as $T_{0}$ conf avancem para além das linhas 
indicadoras da estratégia 'isolamento capacitivo associado à massa térmica'. Neste caso, deve-se verificar se o isolamento resistivo será voltado para o período frio, para o quente ou para ambos.

Por fim, para uma avaliação do clima, o DA1 também permite verificar:

a) Percentual de horas com temperaturas na faixa de conforto, nas quais pode ocorrer ventilação natural sem maiores restrições.

b) Percentual de horas com restrição à ventilação natural. Estas são divididas em:

b1) Horas com temperaturas abaixo da faixa de conforto

b2) Horas com temperaturas acima da faixa de conforto.

Diagrama Antropoclimático 2 (DA2) - Análise de dados do ambiente interno simulado

Nesta etapa, são simulados e analisados dados do ambiente interno. Para a simulação, deve ser considerado o NITRR definido para a nova edificação na etapa anterior, de modo que a grande maioria das $\Delta T_{d}$ in da edificação simulada sejam menores ou iguais ao valor máximo dado pelo modelo adaptativo adotado.

Para simulação, considera-se uma edificação hipotética, sombreada, sem mecanismos para aquecimento/resfriamento, cujas trocas térmicas com o meio ocorrem predominantemente por condução e convecção. A simulação pode ser feita via software ou via equações preditivas. Neste artigo com finalidade demonstrativa, utiliza-se o método preditivo proposto por Krüger et al. (2017).

Para compatibilidade com os modelos adaptativos da ASHRAE (2017), as temperaturas internas do $\operatorname{ar}\left(T_{a \text { in }}\right)$ simuladas e as temperaturas operativas $\left(T_{0}\right)$ do ambiente em projeto são assumidas como iguais. Essa assumpção apoia-se no fato de que, em ambientes internos de edificações sombreadas e com restrições na ventilação, as duas variáveis costumam apresentar valores próximos.

\section{Estrutura do Diagrama Antropoclimático 2 (DA2)}

A seguir, são apresentadas as zonas do DA2 (Figura 4) para diretrizes de projeto.

a) Conforto. Temperaturas cujas diferenças em relação às temperaturas neutras estejam entre $\pm 2,5^{\circ} \mathrm{C}$ ( $90 \%$ de aceitabilidade).

b) Sombreamento. Para Olgyay (2008), havendo conforto sem incidência de radiação solar direta, é recomendado sombreamento. Sendo que as $T_{a}$ in de base horária podem apresentar bastante oscilação, nesta proposta, trabalha-se com as temperaturas médias diárias $\left(T_{a}\right.$ in $\left.\mathrm{m}\right)$. Recomenda-se sombreamento quando, no interior da edificação, as diferenças entre as $T_{a \text { in } m}$ e as $T_{\text {o conf }}$ forem iguais ou maiores que as do limite esquerdo da faixa de conforto.

c) Massa térmica para aquecimento solar. Esta estratégia é recomendada sempre que as diferenças entre as $T_{a \text { in } m}$ e as $T_{\text {o conf }}$ forem menores do que as do limite esquerdo da faixa de conforto. Consideraram-se as recomendações apresentadas por Bogo et al. (1994) e pela Parte 3 da NBR 15.220 (ABNT, 2005).

d) Aumento da velocidade do ar. O modelo de conforto adaptativo adotado prevê o alargamento da faixa de conforto, alterando seu limite direito, caso a velocidade do ar seja aumentada, preservando os valores para o PMV (ASHRAE, 2017). Para 0,6 m/s o aumento é de $1,2^{\circ} \mathrm{C}$; para $0,9 \mathrm{~m} / \mathrm{s}$ é de $1,8^{\circ} \mathrm{C}$; e para a velocidade do ar de $1,2 \mathrm{~m} / \mathrm{s}$ o aumento é de $2,2{ }^{\circ} \mathrm{C}$. Velocidades acima de $0,8 \mathrm{~m} / \mathrm{s}$ são toleradas somente quando os usuários possuem controle sobre a ventilação. Esse aumento na velocidade do ar 
pode ser realizado com ventilação mecânica, uma vez que o clima pode apresentar restrições à ventilação natural em determinados horários.

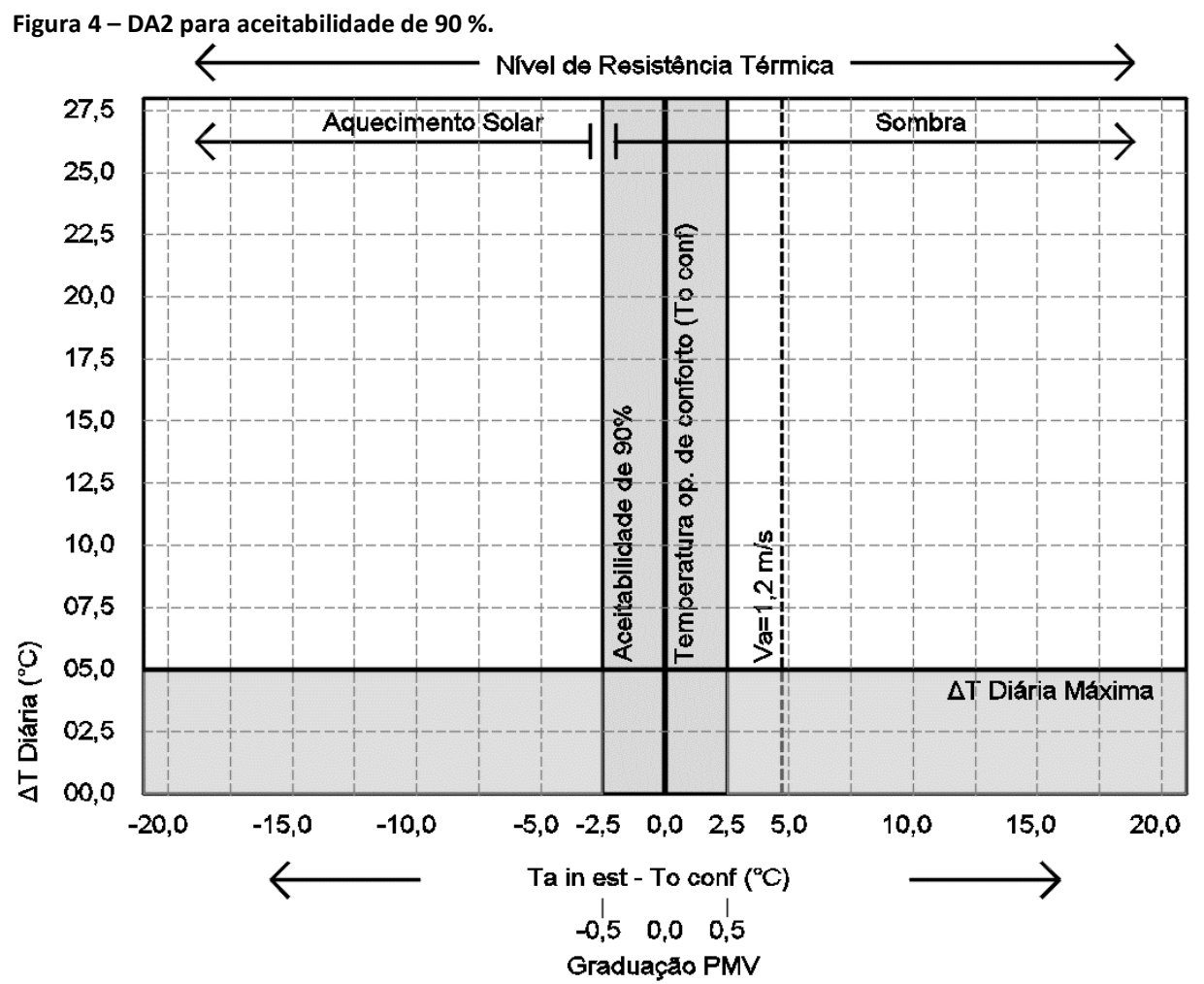

\section{Simulação de dados internos de temperaturas horárias}

O argumento fundamental do método preditivo proposto por Krüger et al. (2017) é: as temperaturas internas do ar de pequenas edificações passivas (sem meios para resfriamento/aquecimento) oscilam conforme a diferença em relação às temperaturas externas. Essa oscilação ocorre a taxas $(\alpha)$ mais ou menos constantes, variando conforme a edificação. $\alpha$ está relacionado ao nível de inércia térmica (NIT) da edificação. Sendo assim, a partir do NITRR, indicado pelo DA1, pode-se obter um valor aproximado para a taxa de variação demandada para uma edificação (Equação 8). As temperaturas internas horárias do ar estimadas são obtidas com a Equação 9.

$$
\begin{array}{cc}
\alpha=\left(\frac{1}{N I T+1}\right)^{2,25} & \text { Equação } 8 \\
T_{a \text { in est }}^{t}=T_{\text {a in est }}^{t-1}+\alpha\left(T_{a \text { ex }}^{t}-T_{\text {a in est }}^{t-1}\right) & \text { Equação } 9 \\
\text { Fonte: Krüger et al. (2017). } &
\end{array}
$$

Na qual, $t$ indica a hora (momento), $T_{a \text { in est }}^{t}$ é a temperatura interna estimada no momento $t, T_{a}^{t-1}$ est é a temperatura estimada no momento $t-1$ e $T_{a}^{t}$ ex é a temperatura externa no momento $t$.

\section{Procedimentos para aplicação do DA2}

A partir das temperaturas horárias do ambiente externo, são simuladas as temperaturas horárias para o interior da edificação em projeto considerando o NITRR. Estes dados devem ser plotados sobre o DA2. No diagrama, será possível checar as demandas por resfriamento/aquecimento, sombreamento e ventilação. Sugere-se, inicialmente, a 
plotagem dos dados anuais e, posteriormente, caso o clima apresente períodos de calor e frio bem definidos, a plotagem de dados por estações.

Comparação com dados resultantes da aplicação do diagrama de Givoni adaptado para o Brasil

Para verificar a existência de diferenças entre os resultados obtidos com a aplicação dos Diagramas Bioclimáticos 1 e 2 e os resultantes da aplicação do Diagrama Bioclimático para Edificações (BBCC) de Givoni, adaptado por Bogo et al. (1994), foram realizadas aplicações em duas etapas:

- Aplicação aos dados do ambiente externo;

- Aplicação aos dados simulados para o ambiente interno.

Embora o Diagrama de Givoni (1992) tenha sido proposto para analisar as condições ambientais internas de edificações, muitos autores o utilizam para analisar condições ambientais externas.

\section{Resultados}

Primeiramente, foram analisados os dados referentes ao ambiente externo utilizando o Diagrama Antropoclimático 1 (DA1) e o Diagrama de Givoni. Na sequência, foram analisados os dados simulados para o ambiente interno com o Diagrama Antropoclimático 2 (DA2) e novamente com o Diagrama de Givoni.

Aplicação dos Diagramas Antropoclimáticos ao clima de Curitiba e comparação dos resultados com os obtidos utilizando o Diagrama de Givoni

\section{Análise dos dados do ambiente externo}

A aplicação do Diagrama Antropoclimático 1 (DA1) tem dois objetivos principais: determinar o NITRR para a futura edificação e determinar a estratégia para atingir o NITRR.

Usualmente, para relacionar as temperaturas de um local com a respectiva faixa de conforto térmico determinada pela ANSI/ASHRAE Standard 55 (ASHRAE, 2017), utilizase plotagem conforme a Figura 5. A partir dela, é possível afirmar que em Curitiba predominam temperaturas horárias baixas (relativamente à faixa de conforto) e que as temperaturas médias diárias também são predominantemente baixas. Porém, não é possível estimar o NITRR.

Alternativamente à Figura 5 , pode-se apresentar um gráfico cujo eixo das ordenadas apresente as diferenças entre as temperaturas externas do $\operatorname{ar}\left(T_{a \text { ex }}\right)$ e as temperaturas operativas de conforto ( $T_{\text {o conf }}$ ). Neste caso (Figura 6 ), as $T_{\text {o conf }}$ são apresentadas como um segmento de reta horizontal passando pelo ponto zero no eixo das ordenadas. Esta representação cria uma escala termométrica com foco nas $T_{\text {o conf }}$ e na faixa de conforto, ou seja, na percepção térmica humana.

Ao se passar as diferenças entre as $T_{a \text { ex }}$ e as $T_{\text {o conf }}$ para o eixo das abscissas e ao se inserir as amplitudes térmicas diárias $\left(\Delta T_{d}\right)$ no eixo das ordenadas, tem-se a estrutura para o DA1. Ou seja, o DA1 preserva a faixa de conforto térmico determinada pela ANSI/ASHRAE Standard 55 (ASHRAE, 2017), embora a represente de modo diferente do usual. 


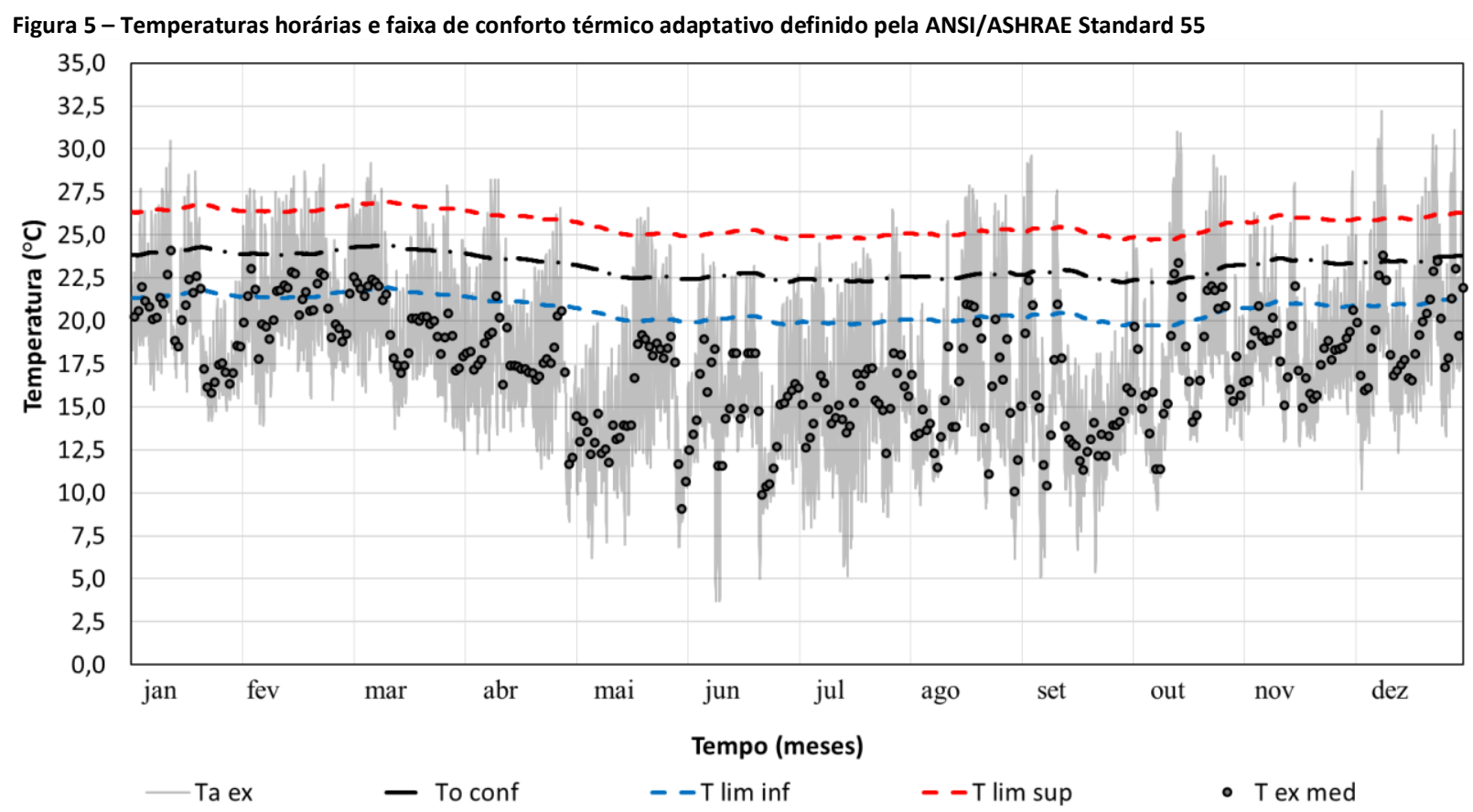

Fonte: o autor.

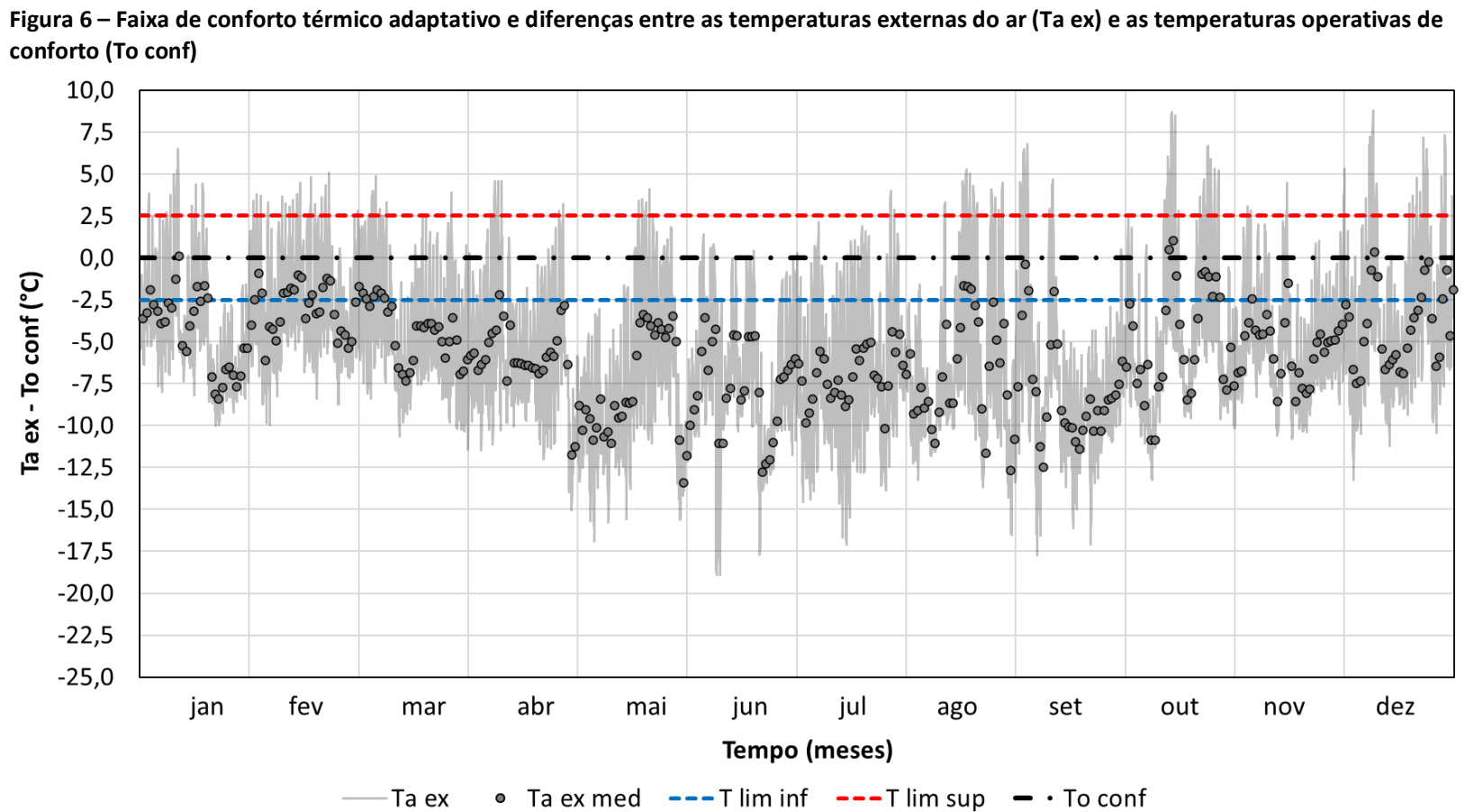

Fonte: o autor.

A determinação do NITRR para pequenas edificações no clima de Curitiba apoiou-se nas Figura $7 \mathrm{a}$ e Figura $7 \mathrm{~b}$. Comparativamente à Figura 5 e à Figura 6, as Figura 7 a e Figura $7 \mathrm{~b}$ permitem observar de modo mais claro que, em Curitiba, as $\Delta T_{d}$ são excessivas na maior parte do ano se considerada a amplitude de referência de $5^{\circ} \mathrm{C}$. O DA1 indica ainda que, para pequenas edificações a serem edificadas em Curitiba, o nível de inércia térmica relativo recomendado (NITRR) para amortecimento das amplitudes é maior do que 2.0 problema de desconforto por frio é predominantemente noturno e durante as noites não ocorre desconforto por calor no ambiente externo. Quanto ao período diurno, as temperaturas se situam tanto na faixa de conforto quanto nas faixas de desconforto por frio (à esquerda da faixa de conforto) e por calor (à direita). 


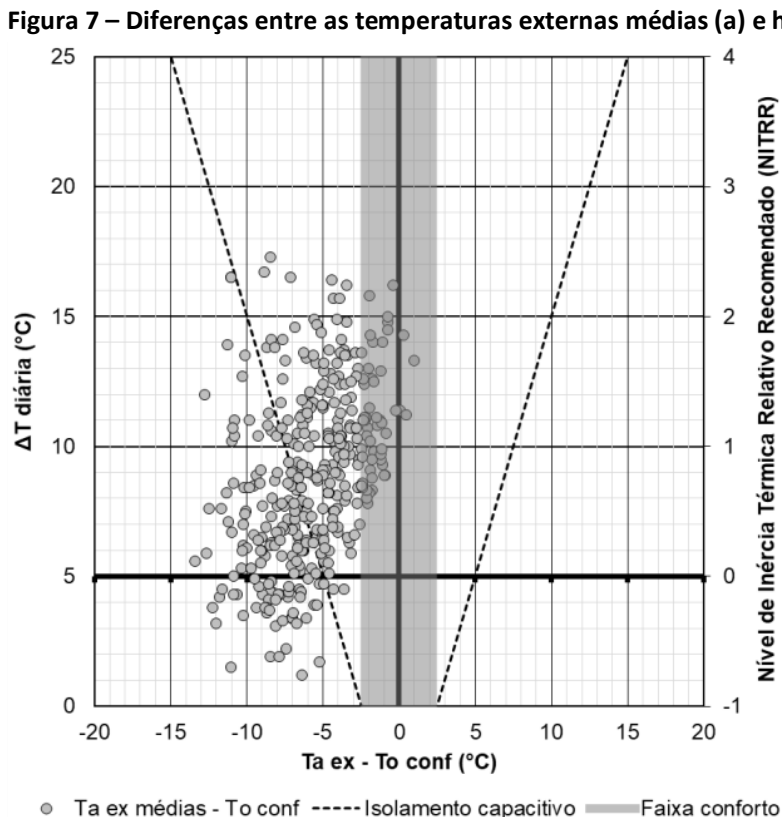

- Ta ex médias - To conf ------|solamento capacitivo —Faixa conforto

(a)

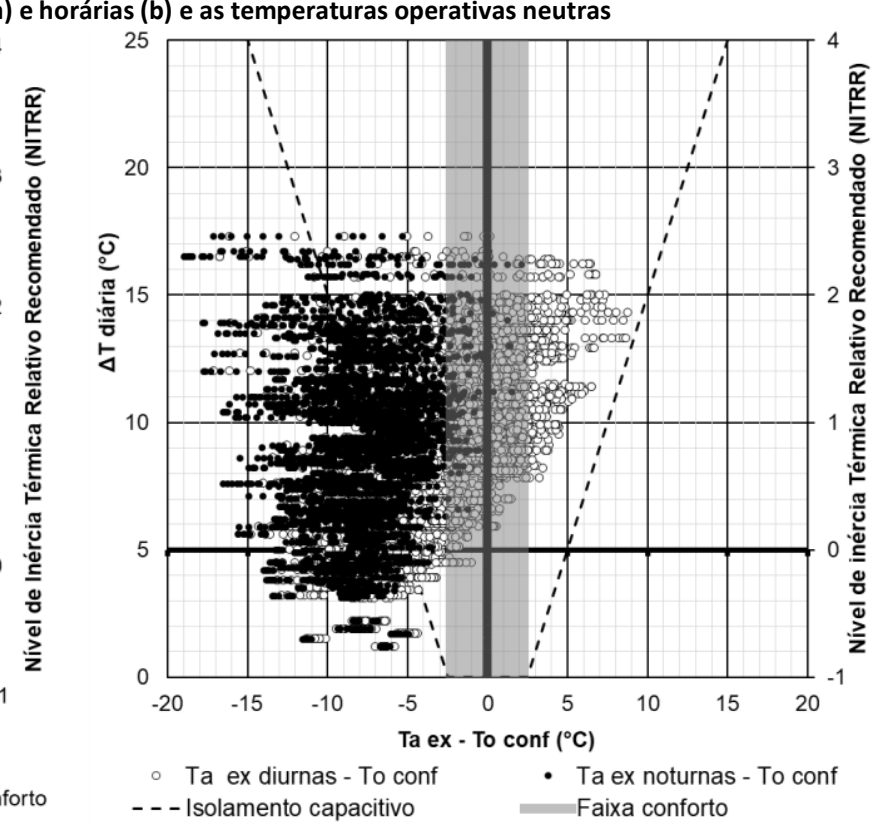

(b)

Fonte: 0 autor.

A análise dos dados em planilha eletrônica associada ao DA1 possibilitou quantificar (Tabela 1) com precisão os dias com $\Delta T_{d}$ dentro e fora da faixa de $5^{\circ} \mathrm{C}$. As $\Delta T_{d}$ foram excessivamente altas na grande maioria dos dias (315) do ano de 2008, confirmando a necessidade de inércia térmica.

Conhecer o valor das $\Delta T_{d}$ possibilitou calcular o NITRR e o valor de a para estimar as temperaturas internas de uma pequena edificação hipotética. Para isso, foram utilizados as $\Delta T_{d}$ correspondentes ao percentil 99. Neste percentil, o NITRR é 2,3, o que indica que, para respeitar o limite de $5^{\circ} \mathrm{C}$, as amplitudes térmicas diárias internas $\left(\Delta T_{d \text { in }}\right)$ devem corresponder a uma fração das amplitudes térmicas diárias externas $\left(\Delta T_{\text {dex }}\right)$, ou seja: $\Delta T_{\text {din }}=\Delta T_{\text {dex }} /(2,3+1)$.

Quanto ao conforto térmico, o ano de 2008 em Curitiba foi predominantemente desconfortável (83,3\% das horas), principalmente devido ao frio, para o qual o índice graus-hora para aquecimento foi de $34.589,8^{\circ} \mathrm{Ch}$.

\begin{tabular}{ccc} 
Tabela 1 - Resultados da plotagem dos dados do ambiente térmico externo de Curitiba sobre o DA1 & \\
\hline Variável & Resultado & Porcentagem \\
\hline Dias com $\Delta \mathrm{Td}>5{ }^{\circ} \mathrm{C}$ & 315 & $86,3 \%$ \\
\hline Dias com $\Delta \mathrm{T}<=5$ & 50 & $13,7 \%$ \\
\hline$\Delta \mathrm{Td}$ máx & $17,3{ }^{\circ} \mathrm{C}$ & - \\
\hline$\Delta \mathrm{Td}$ no percentil 99 & $16,5^{\circ} \mathrm{C}$ & - \\
\hline NITRR (considerando a $\Delta \mathrm{Td}$ máx) & 2,46 & - \\
\hline NITRR (considerando a $\Delta \mathrm{Td}$ no percentil 99$)$ & 2,30 & - \\
\hline$\alpha$ (considerando a $\Delta \mathrm{Td}$ máx) & 0,061 & - \\
\hline$\alpha$ (considerando a $\Delta \mathrm{Td}$ no percentil 99$)$ & 0,068 & - \\
\hline Ta ex mínima & $3,7{ }^{\circ} \mathrm{C}$ & - \\
\hline Ta ex média & $17,4{ }^{\circ} \mathrm{C}$ & - \\
\hline Ta ex máxima & $32,2{ }^{\circ} \mathrm{C}$ & - \\
\hline Graus hora para aquecimento (GHA) & $34.589,8$ & - \\
\hline Graus hora para resfriamento (GHR) & 565,4 & - \\
\hline Horas com faixa de conforto & 1.741 & $16,8 \%$ \\
\hline Horas com demanda por aquecimento & 6.925 & $79,1 \%$ \\
\hline Horas com demanda por resfriamento & 364 & $4,2 \%$ \\
\hline
\end{tabular}

Fonte: o autor. 
A plotagem sobre o diagrama de Givoni (Figura 8) também indicou que se trata de clima predominantemente desconfortável devido ao frio. No entanto, classificou mais horas como confortáveis (29,1\% - Tabela 2), comparativamente ao DA1 (16,8\% - Tabela 1). Essa discrepância é devido à diferença de largura entre as faixas de temperaturas confortáveis $\left(5^{\circ} \mathrm{C} \mathrm{e} 11^{\circ} \mathrm{C}\right)$, à flutuação da faixa adaptativa e à exclusão, no diagrama de Givoni, das temperaturas quando a umidade relativa é maior do que $80 \%$.

Figura 8 - Dados horários de temperatura e umidade relativa de Curitiba plotados sobre o Diagrama de Givoni

ZONAS UR [\%]

1. Conforto

2. Ventilacao

3. Resfriamento Evaporativo

4. Alta Inércia Témica p/ Resfr.

5. Ar Condicionado

6. Umidificação

7. Alta Inércia Témica/ Aquecimento Solar ô

8. Aquecimento Solar Passino

9. Aquecimento Artificial

10.Ventilação/ Alta Inércia

11.Vent./Alta Inércia/Resf. Evap.

12.Alta Inércia/Resf. Evap.

0

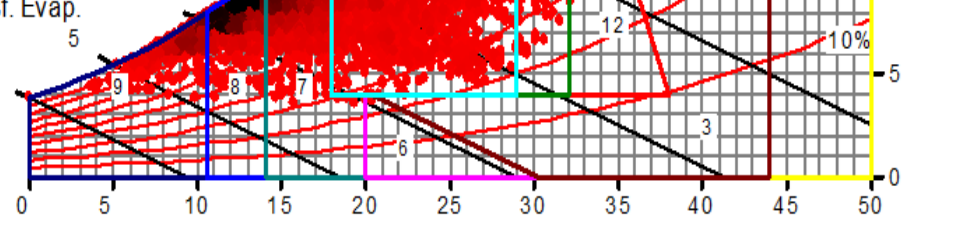

TBS $\left[{ }^{\circ} \mathrm{C}\right]-U F S C-E C V-L a b E E E-N P C$

Fonte: Elaborada pelo autor no programa Analysis Bio, versão 2.2 (LABEEE, 2010).

Quanto às amplitudes térmicas, o diagrama adaptado do modelo de Givoni não possibilita analisar essa variável. Embora o diagrama de Givoni oriente para utilização da estratégia 'alta inércia térmica / aquecimento solar' em 45,1\% das horas do ano (Tabela 2), o foco dessa estratégia está no aquecimento, pois é uma orientação baseada na análise de temperaturas horárias, sem contextualização com as demais temperaturas do dia no qual elas ocorreram. O diagrama de Givoni também não estima a 'intensidade' ou o nível de inércia recomendado.

\begin{tabular}{|c|c|}
\hline Variável & $\begin{array}{c}\text { Porcentagem das } \\
\text { horas do ano }\end{array}$ \\
\hline Temperaturas na faixa de conforto (1) & $29,1 \%$ \\
\hline Temperaturas fora da faixa de conforto & $70,9 \%$ \\
\hline Demanda por aquecimento & $67,4 \%$ \\
\hline Demanda por resfriamento & $3,5 \%$ \\
\hline 2 - Ventilação & $2,9 \%$ \\
\hline 3 - Resfriamento Evaporativo & $0,0 \%$ \\
\hline 4 - Alta Inércia Térmica $p$ / Resfriamento & $0,0 \%$ \\
\hline 5 - Ar Condicionado & $0,0 \%$ \\
\hline 6 - Umidificação & $0,1 \%$ \\
\hline 7 - Alta Inércia Térmica/Aquecimento Solar & $45,1 \%$ \\
\hline 8 - Aquecimento Solar Passivo & $17,5 \%$ \\
\hline 9- Aquecimento Artificial & $4,9 \%$ \\
\hline 10 - Ventilação/Alta Inércia & $0,0 \%$ \\
\hline 11 - Ventilação/Alta Inércia/Resfriamento Evaporativo & $0,5 \%$ \\
\hline 12 - Alta Inércia/Resfriamento Evaporativo & $0,0 \%$ \\
\hline
\end{tabular}

Fonte: o autor. 
Definido o NITRR, o próximo passo foi determinar a estratégia prioritária para alcançálo a partir das características termofísicas das paredes internas e da envoltória. Para isso, foram avaliadas diferenças entre as $T_{a \text { exm }}$ e as $T_{\text {o conf }}$ (Figura $7 a$ ) e as diferenças entre as

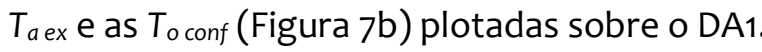

Somente em $53(14,5 \%$ ) dos dias do ano (Tabela 3) as temperaturas médias diárias (Figura 6) ou as diferenças entre as $T_{a \text { exm }}$ e as $T_{\text {o conf }}$ (Figura $7 a$ ) ficaram sobre a faixa de conforto. Nos demais 312 dias, as diferenças entre as $T_{a \text { exm }}$ e as $T_{\text {oconf }}$ ficaram à esquerda na Figura 7a. Ou seja, em Curitiba, aumentar apenas a inércia térmica (via massa térmica) é insuficiente. É necessário prevenir as perdas térmicas e, para isso, deve-se associar a massa térmica (das paredes internas e externas) com o isolamento resistivo externo.

Tabela 3 - Estratégias para atingir o NITRR para Curitiba considerando médias diárias

\begin{tabular}{|c|c|c|}
\hline Estratégia & Dias & Porcentagem \\
\hline $\begin{array}{l}\text { Isolamento capacitivo e resistivo (paredes externas) + massa térmica (paredes } \\
\text { internas) para frio. } \\
\text { (Ta ex } \mathrm{m}-\text { To conf) }<-2,5^{\circ} \mathrm{C} .\end{array}$ & 312 & $85,5 \%$ \\
\hline $\begin{array}{l}\text { Isolamento capacitivo (paredes externas) + massa térmica (paredes internas). } \\
\qquad-2,5^{\circ} \mathrm{C}<=(\text { Ta ex } \mathrm{m} \text { - To conf })<=2,5^{\circ} \mathrm{C} \text {. }\end{array}$ & 53 & $14,5 \%$ \\
\hline $\begin{array}{l}\text { Isolamento capacitivo e resistivo (paredes externas) + massa térmica (paredes } \\
\text { internas) para calor. } \\
\text { (Ta ex } \mathrm{m}-\text { To conf) }>+2,5^{\circ} \mathrm{C} .\end{array}$ & 0 & $0,0 \%$ \\
\hline
\end{tabular}

Fonte: o autor.

Quando analisadas as diferenças entre as $T_{a \text { ex }}$ e as $T_{\text {o conf }}$ (Figura 7a), em 293 dias (Tabela 4) ocorreram diferenças plotadas na zona 'isolamento capacitivo e resistivo + massa térmica', concordando com a análise considerando as temperaturas médias diárias.

\begin{tabular}{|c|c|c|}
\hline Estratégia & Dias & Porcentagem \\
\hline $\begin{array}{l}\text { Isolamento capacitivo e resistivo (paredes externas) + massa térmica (paredes } \\
\text { internas) para frio. } \\
\text { (Ta ex } \mathrm{m}-\text { To conf) }<-2,5^{\circ} \mathrm{C} .\end{array}$ & 293 & $80,3 \%$ \\
\hline $\begin{array}{l}\text { Isolamento capacitivo (paredes externas) + massa térmica (paredes internas). } \\
\qquad-2,5^{\circ} \mathrm{C}<=(\text { Ta ex } \mathrm{m}-\text { To conf })<=2,5{ }^{\circ} \mathrm{C} \text {. }\end{array}$ & 72 & $19,7 \%$ \\
\hline $\begin{array}{l}\text { Isolamento capacitivo e resistivo (paredes externas) + massa térmica (paredes } \\
\text { internas) para calor. } \\
\text { (Ta ex } \mathrm{m}-\text { To conf) }>+2,5^{\circ} \mathrm{C} .\end{array}$ & 0 & $0,0 \%$ \\
\hline
\end{tabular}

Fonte: o autor.

Da aplicação do DA1 para Curitiba, concluiu-se que pequenas edificações, para apresentarem $\Delta T_{\text {din }}$ adequadas ao modelo adaptativo, devem apresentar NITRR próximo de 2,3 e, para atingir esse valor, devem utilizar paredes externas com isolamento (capacitivo e resistivo) e paredes internas pesadas. Essas recomendações estão em concordância com as constantes na NBR 15.220 (ABNT, 2005).

\section{Análise dos dados estimados para o ambiente interno em Curitiba}

A plotagem sobre o Diagrama Antropoclimático 2 (DA2) teve como objetivos verificar:

a) Números de horas em conforto térmico;

b) Número de dias com demanda por sombreamento;

C) Dias e horas com demanda por aquecimento solar e

d) Demanda por aumento da velocidade do ar interno.

Simulado o NITRR para o clima de Curitiba (Figura 9), a amplitude térmica diária máxima $\left(\Delta T_{d \text { in máx }}\right.$ ) passou para $6^{\circ} \mathrm{C}$ (baixa, se comparada com a correspondente externa, 17,3 
$\left.{ }^{\circ} \mathrm{C}\right)$. Houve redução dos valores extremos das temperaturas do ar (Figura 9 e Figura 10b). A temperatura mínima passou de $3,7^{\circ} \mathrm{C}$ (Tabela 5) para $9,4^{\circ} \mathrm{C}$ e a temperatura máxima de $32,2{ }^{\circ} \mathrm{C}$ para $25,7{ }^{\circ} \mathrm{C}$. A temperatura média interna do ambiente simulado (Tabela 5 ) permaneceu a mesma do ambiente externo, $17,4{ }^{\circ} \mathrm{C}$ (Tabela 1).

Figura 9 - Diferenças entre temperaturas internas estimadas e temperaturas operativas de conforto

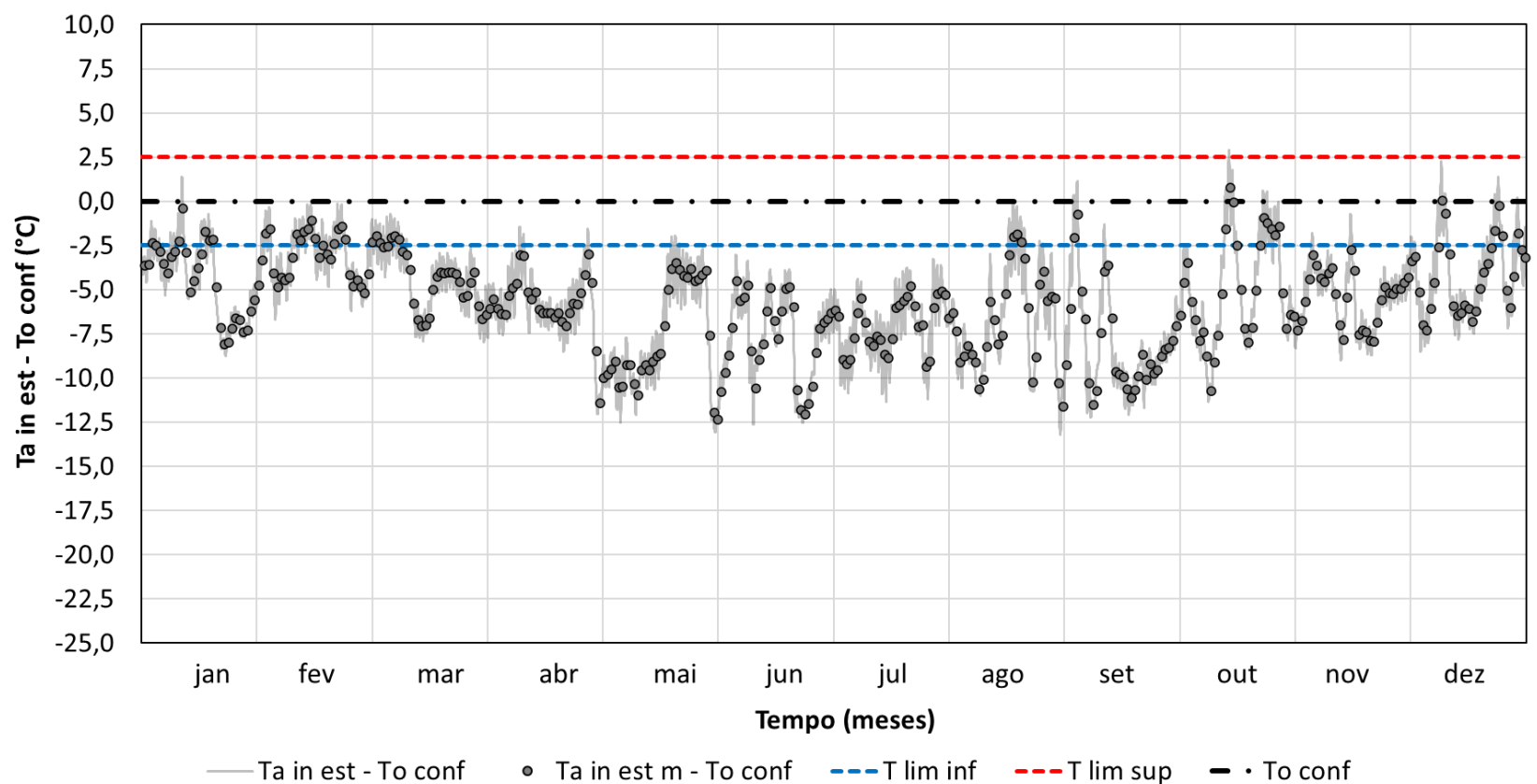

Fonte: o autor.

\begin{tabular}{ccc} 
Tabela 5 - Resultados da plotagem das temperaturas internas estimadas sobre o DA2 & \\
\hline Variável & Resultado & Porcentagem \\
\hline Dias com $\Delta \mathrm{Td}>5{ }^{\circ} \mathrm{C}$ & 10 & $2,7 \%$ \\
\hline Dias com $\Delta \mathrm{T}<=5$ & 355 & $97,3 \%$ \\
\hline$\Delta \mathrm{Td}$ máx & $6,0{ }^{\circ} \mathrm{C}$ & - \\
\hline$\Delta \mathrm{Td}$ no percentil 99 & $5,3{ }^{\circ} \mathrm{C}$ & - \\
\hline Ta in mínima & $9,4{ }^{\circ} \mathrm{C}$ & - \\
\hline Ta ex média & $17,4{ }^{\circ} \mathrm{C}$ & - \\
\hline Ta in máxima & $25,7{ }^{\circ} \mathrm{C}$ & - \\
\hline Graus hora para aquecimento & $30.311,2$ & - \\
\hline Graus hora para resfriamento & 1,1 & - \\
\hline Horas com demanda por aquecimento & 1.133 & $12,9 \%$ \\
\hline Horas com demanda por resfriamento & 7.623 & $87,0 \%$ \\
\hline Horas com demanda por aquecimento & 4 & $0,05 \%$ \\
\hline - Diurnas & 3776 & $43,1 \%$ \\
\hline - Noturnas & 3847 & $43,9 \%$ \\
\hline a) Horas com temperaturas na faixa de conforto & \\
\hline Horas com temperaturas acima da faixa de conforto & 4 & $0,05 \%$ \\
\hline - Diurnas & 0,0 & $0,0 \%$ \\
\hline - Noturnas & 44 & $12,1 \%$ \\
\hline b) Dias com demanda por sombreamento & 321 & $87,9 \%$ \\
\hline c) Dias com demanda por aquecimento solar. & 3.636 & $83,0 \%$ \\
\hline c.1) Horas diurnas com demanda por aquecimento solar. & 4 & $0,05 \%$ \\
\hline d) Horas com demanda por aumento da velocidade do ar & \\
\hline
\end{tabular}
Fonte: $\mathrm{o}$ autor.

A inércia térmica aplicada à edificação também reduziu o índice graus-hora para aquecimento, de $34.589,8^{\circ} \mathrm{Ch}$ para $30.311,2^{\circ} \mathrm{Ch}$, e o índice graus-hora para resfriamento, de $565,4^{\circ} \mathrm{Ch}$ para $1,1^{\circ} \mathrm{Ch}$. 
O DA2 (Figura 10a e Figura 10b) mostrou que as amplitudes térmicas passaram a ser aceitáveis na maior parte do tempo e que as diferenças entre as condições térmicas noturnas e diurnas foram reduzidas.

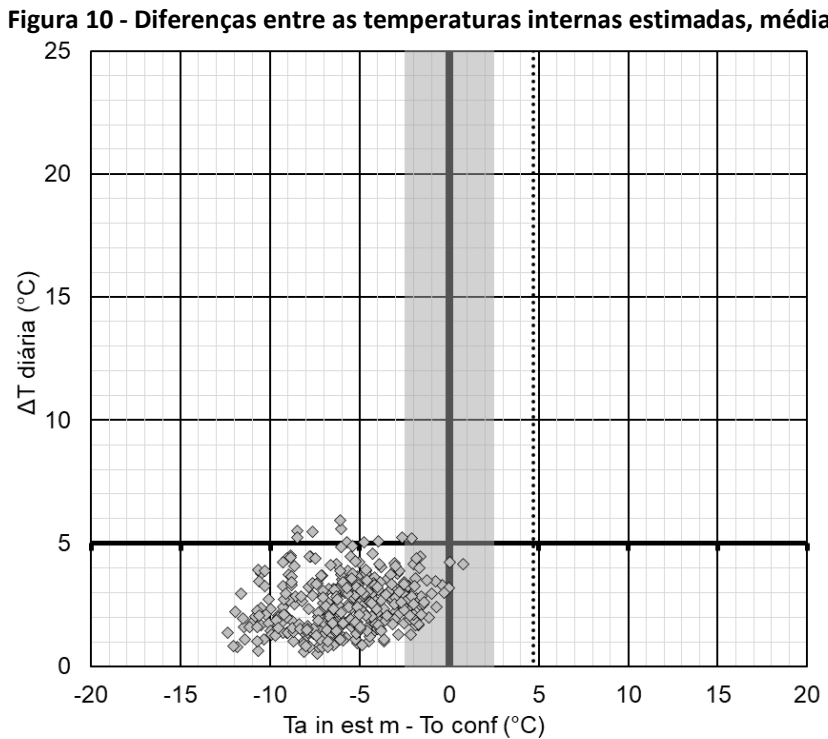

$\diamond$ Ta in est $\mathrm{m}$ - To conf Faixa conforto ........ Aumento velocidade do ar

(a)

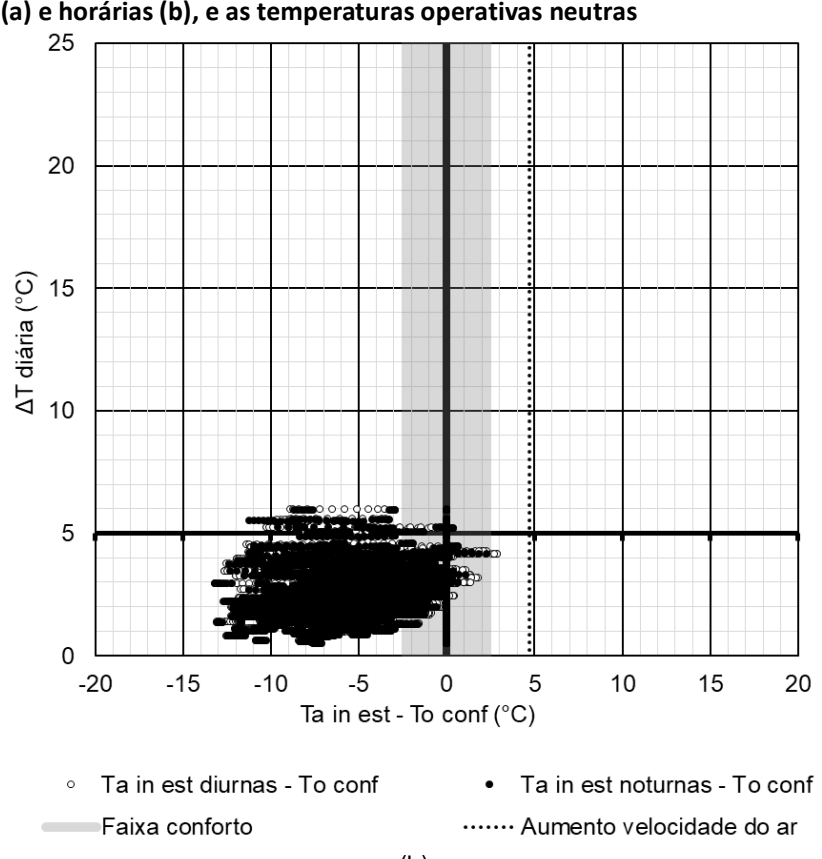

(b)

Fonte: o autor.

As condições simuladas confirmaram a adequação do NITRR e da estratégia para atingilo, adequando as amplitudes térmicas internas. Também indicaram, como próximo passo, para adequar as temperaturas internas, a estratégia aquecimento solar, indicada para $87,9 \%$ dos dias do ano curitibano (Tabela 5 ).

Comparativamente à aplicação do diagrama de Givoni aos dados do ambiente externo (Figura 8), a aplicação desse mesmo diagrama aos dados estimados para o ambiente interno (Figura 11) indicou aumento do desconforto por frio, embora com redução na necessidade de aquecimento artificial (de $4,9 \%$ das horas para $0,7 \%$ ), resultante do aumento do patamar das temperaturas mínimas (de $3,7^{\circ} \mathrm{C}$ para $9,4^{\circ} \mathrm{C}$ ).

Figura 11 - Dados horários simulados para o ambiente interno em Curitiba plotados sobre o Diagrama de Givoni

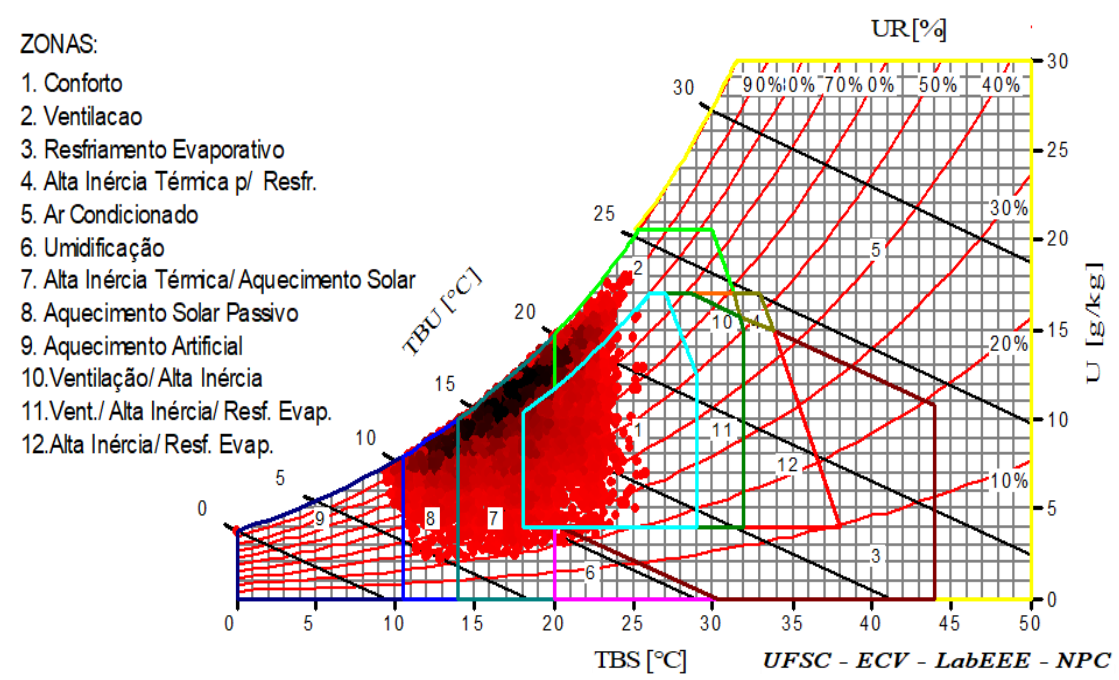

Fonte: Elaborada pelo autor no programa Analysis Bio, versão 2.2 (LABEEE, 2010). 
Comparativamente à análise dos dados internos utilizando o DA2, o diagrama de Givoni também apontou para a necessidade de aquecimento solar (Tabela 6), mas com menos ênfase que o DA2, que apontou para a utilidade dessa estratégia em $87,9 \%$ dos dias e em 83 \% das horas diurnas. Ou seja, houve concordância nas estratégias prioritárias e divergência na ênfase dada por cada diagrama.

\begin{tabular}{cc} 
Tabela $\mathbf{6}$ - Resultados da plotagem dos dados horários simulados para ambiente interno sobre o Diagrama de Givoni \\
\hline Variável & Porcentagem das horas do ano \\
\hline Temperaturas na faixa de conforto (1) & $21,3 \%$ \\
\hline Temperaturas fora da faixa de conforto & $78,7 \%$ \\
\hline Demanda por aquecimento & $67,5 \%$ \\
\hline Demanda por resfriamento & $11,1 \%$ \\
\hline 2 - Ventilação & $10,8 \%$ \\
\hline 3 - Resfriamento Evaporativo & $0,2 \%$ \\
\hline 4 - Alta Inércia Térmica p/ Resfriamento & $0,0 \%$ \\
\hline 5 - Ar Condicionado & $0,0 \%$ \\
\hline 6 - Umidificação & $0,1 \%$ \\
\hline - Alta Inércia Térmica/Aquecimento Solar & $50,5 \%$ \\
\hline 8 - Aquecimento Solar Passivo & $16,3 \%$ \\
\hline 9 - Aquecimento Artificial & $0,7 \%$ \\
\hline 10 - Ventilação/Alta Inércia & $0,0 \%$ \\
\hline 11 - Ventilação/Alta Inércia/Resfriamento Evaporativo & $0,0 \%$ \\
\hline 12 - Alta Inércia/Resfriamento Evaporativo & $0,0 \%$ \\
\hline
\end{tabular}
Fonte: o autor.

\section{Considerações finais}

Este trabalho apresentou diagramas de apoio ao processo de projeto adaptados à ideia do conforto térmico adaptativo e voltados para pequenas edificações com consumo energético quase nulo. Os diagramas propostos possuem faixa de conforto variável e analisam dois aspectos dos dados da variável temperatura: a flutuação (amplitudes diárias) e a posição dos seus valores em relação à faixa de valores confortáveis.

Enquanto o diagrama de Givoni foi desenvolvido para análise de dados de ambientes internos, o DA1 é voltado para análise de dados do ambiente externo e o DA2 para análise de dados medidos ou simulados do ambiente interno.

A aplicação do DA1 ao clima de Curitiba indicou que as amplitudes térmicas diárias foram excessivas em 315 dias do ano $(86,3 \%)$ se considerado o limite de $5^{\circ} \mathrm{C}$, contrastando com o diagrama de Givoni, que não possibilita visualizar essa questão. Embora o diagrama de Givoni oriente para utilização da estratégia 'alta inércia térmica / aquecimento solar' em 45,1\% das horas do ano de Curitiba, o foco dessa recomendação está no aquecimento.

Quando analisados os dados internos estimados, percebeu-se que as diferenças entre as faixas de conforto dos diagramas impactam no dimensionamento das demandas por aquecimento e resfriamento. O diagrama de Givoni indicou necessidade de aquecimento solar em $67,5 \%$ das horas do ano, enquanto o DA2 recomendou aquecimento em $87,9 \%$ dos dias do ano e em $83 \%$ das horas diurnas. O fato de o diagrama de Givoni classificar como desconfortáveis as condições nas quais ocorre umidade relativa acima de $80 \%$ também resulta em diferenças nas avaliações. Enquanto o DA2 praticamente não indicou necessidade de resfriamento, o diagrama de Givoni apontou essa necessidade em $11,1 \%$ das horas do ano. Isso, a despeito de a faixa de conforto adaptativa utilizada apresentar apenas $5{ }^{\circ} \mathrm{C}$ de largura e a do diagrama de Givoni adaptado apresentar $11^{\circ} \mathrm{C}$. A discrepância entre os resultados explicita a necessidade de diagramas específicos para os modelos adaptativos de conforto térmico. 
Sobre a aplicação dos diagramas antropoclimáticos em duas etapas, evidenciou-se que o atendimento à demanda por maior inércia impacta significativamente as demais demandas, o que justifica a sua prioridade. Para trabalhos futuros, cabe avaliar os diagramas com outros modelos adaptativos. Também cabe analisar a inclusão de novas zonas de diretrizes para projetos.

\section{Referências}

ABNT - ASSOCIAÇÃO BRASILEIRA DE NORMAS TÉCNICAS. NBR 15.220: Desempenho térmico de edificações. Parte 3: Zoneamento bioclimático brasileiro e diretrizes construtivas para habitações unifamiliares de interesse social. Rio de Janeiro: Associação Brasileira de Normas Técnicas, 2005.

ABNT/CB-055 - ASSOCIAÇÃO BRASILEIRA DE NORMAS TÉCNICAS / COMITÊ DE REFRIGERAÇÃO, ARCONDICIONADO, VENTILAÇÃO E AQUECIMENTO - CB-55. $3^{\circ}$ Projeto Revisão ABNT NBR 16401-2. Rio de Janeiro: Associação Brasileira de Normas Técnicas, 2016.

ASHRAE - AMERICAN SOCIETY OF HEATING, REFRIGERATING, AND AIR-CONDITIONING ENGINEERS. ASHRAE Standard 55-2017 - Thermal Environmental Conditions for Human Occupancy. USA, Atlanta: 2017.

AULICIEMS, A. Psycho-Physiological Criteria for Global Thermal Zones of Building Design. International Journal of Biometeorology, v. Complement, p. 69-86, 1983.

BOGO, A.; et al. Bioclimatologia Aplicada ao Projeto de Edificações Visando o Conforto Térmico. Relatório Interno 02/94. Florianópolis: 1994.

DE DEAR, R.; BRAGER, G.; COOPER, D. Developing an adaptive model of thermal comfort and preference - Final Report on RP-884. Sydney: ASHRAE, 1997.

EVANS, J. M. Evaluating comfort with varying temperatures: a graphic design tool. Energy and Buildings, v. 35, p. 87-93, 2003. DOI: https://doi.org/10.1016/s0140-6701(03)92067-4

GIVONI, B. Comfort, climate analysis and building design guidelines. Energy and Buildings, v. 18, n. 1, p. 11-23, 1992.

JUNKER, M.; KOLLER, T.; MONN, C. An assessment of indoor air contaminants in buildings with recreational activity. Science of the Total Environment, v. 246, n. 2-3, p. 139-152, 2000. DOI: https://doi.org/10.1016/s00489697(99)00452-0

KRÜGER, E. L. et al. Proposition of a simplified method for predicting hourly indoor temperatures in test cells. Ambiente Construído, v. 17, n. 3, p. 57-70, 2017. DOI: https://doi.org/10.1590/s1678-86212017000300162

LABEEE - LABORATÓRIO DE EFICIÊNCIA ENERGÉTICA EM EDIFICAÇÕES. Analysis Bio. Versão 2.2. Florianópolis: LABEEE, 2010. Disponível em: https://labeee.ufsc.br/downloads/softwares/analysis-bio.

NICOL, F.; HUMPHREYS, M. Adaptive thermal comfort and sustainable thermal standards for buildings. Energy and buildings, v. 34, n. 6, p. 563-572, 2002. DOI: https://doi.org/10.1016/50378-7788(02)00006-3

OLGYAY, V. Arquitectura y Clima. Manual de diseño bioclimático para arquitectos y urbanistas. 5a ed. Barcelona: Gustavo Gili, 2008.

PEREIRA, I. M.; ASSIS, E. S. De. Avaliação de modelos de índices adaptativos para uso no projeto arquitetônico bioclimático. Ambiente Construído, v. 10, n. 1, p. 31-51, 2010. DOI: https://doi.org/10.1590/s1678-86212010000100002

RUBEL, F.; KOTTEK, M. Comments on: "The thermal zones of the Earth" by Wladimir Köppen (1884).

Meteorologische Zeitschrift, v. 20, n. 3, p. 361-365, 2011. DOI: https://doi.org/10.1127/0941-2948/2011/0258 
SZOKOLAY, Steven.V. Introduction to architectural science: the basis of sustainable design. 2 ed.: Elsevier Ltd., 2008.

VELLEI, M. et al. The influence of relative humidity on adaptive thermal comfort. Building and Environment, v. 124, p. 171-185, 2017. DOI: https://doi.org/10.1016/j.buildenv.2017.08.005

VERBEKE, S.; AUDENAERT, A. Thermal inertia in buildings: A review of impacts across climate and building use. Renewable and Sustainable Energy Reviews, v. 82, n. November 2016, p. 2300-2318, 2018. DOI:

https://doi.org/10.1016/j.rser.2017.08.083

ZÖLD, A.; SZOKOLAY, S. PLEA Note 2: Thermal Insulation. Passive and Low Energy Architecture International, 1997.

\section{${ }^{1}$ Leandro Carlos Fernandes}

Arquiteto. Doutor. Professor adjunto na Universidade Federal do Paraná. Endereço postal: Centro Politécnico, Setor de Exatas, Edifício PA, $4^{\circ}$ andar, R. Cel. Francisco Heráclito dos Santos, N 100, CEP 81531-980, Bairro Jardim das Américas, Curitiba/PR. 